\section{Effects of lead pollution on Ammonia parkinsoniana (foraminifera): ultrastructural and microanalytical approaches}

\author{
F. Frontalini, ${ }^{1}$ D. Curzi, ${ }^{1}$ F.M. Giordano, ${ }^{1}$ \\ J.M. Bernhard, ${ }^{2}$ E. Falcieri, ${ }^{1,3}$ R. Coccioni ${ }^{1}$ \\ ${ }^{1}$ Department of Earth, Life and \\ Environmental Sciences, University \\ of Urbino Carlo Bo, Italy \\ ${ }^{2}$ Geology and Geophysics Department, \\ Woods Hole Oceanographic Institution, \\ Woods Hole, MA, USA \\ ${ }^{3} \mathrm{CNR}$, Molecular Genetics Institute and \\ Rizzoli Orthopaedic Institute, Bologna, \\ Italy
}

\section{Abstract}

The responses of Ammonia parkinsoniana (Foraminifera) exposed to different concentrations of lead $(\mathrm{Pb})$ were evaluated at the cytological level. Foraminifera-bearing sediments were placed in mesocosms that were housed in aquaria each with seawater of a different lead concentration. On the basis of transmission electron microscopy and environmental scanning electron microscopy coupled with energy dispersive spectrometer analyses, it was possible to recognize numerous morphological differences between untreated (i.e., control) and treated (i.e., lead enrichment) specimens. In particular, higher concentrations of this pollutant led to numerical increase of lipid droplets characterized by a more electron-dense core, proliferation of residual bodies, a thickening of the organic lining, mitochondrial degeneration, autophagosome proliferation and the development of inorganic aggregates. All these cytological modifications might be related to the pollutant-induced stress and some of them such as the thickening of organic lining might suggest a potential mechanism of protection adopted by foraminifera.

\section{Introduction}

In some regions of the world, most of coastal marine environments including transitional ones (i.e., lagoons, coastal lakes and estuaries) are regularly affected by industrial and sewage discharges including both organic and inorganic sources that undermine the ecological quality of the environment. Among the different kinds of pollutants, the trace elements also known as heavy metals appear to have the most deleterious effects on biota and are con- sidered as the most toxic and persistent inorganic environmental pollutants. ${ }^{1,2}$ Unlike toxic organic compounds, heavy metals cannot be degraded but undergo bioaccumulation through the food web. ${ }^{3,4}$ Among heavy metals, lead $(\mathrm{Pb})$ is found naturally in the environment and associated with zinc, silver and copper in ore. It is widely used for a number of industrial applications (cables, pipelines, paints and pesticides) and the main anthropogenic input is through the fossil-fuel combustion of engine fuel where the lead serves as an anti-knock additive. During combustion, lead is burned and several lead salts (chlorines, bromines, oxides) are produced and released through the exhausts of automobiles: the salts are emitted to the atmosphere as aerosols. ${ }^{5}$ Over the past few decades, this application has markedly decreased with the banning of the anti-knock additive both in Europe and North America. ${ }^{6}$ Lead released in the atmosphere ultimately will precipitate in rain and snow to accumulate in the watershed and soils, where it can affect the indigent biota. ${ }^{7}$ Lead is one of the top four metals that have the most damaging effects on organisms such as shellfish, phytoplankton, and humans because it mimics other biologically essential metals (substitution of $\mathrm{Ca}^{2+}, \mathrm{Mg}^{2+}, \mathrm{Fe}^{2+}, \mathrm{Zn}^{2+}$, and $\left.\mathrm{Na}^{+}\right){ }^{8,9}$ Lead can be accumulated in individual organisms, but also throughout food webs (bioaccumulation).

Living organisms have been commonly applied as biological indicators (bioindicators) of pollution to evaluate the overall health of ecosystems and their component parts (i.e., sediment and water). It was estimated that over $40 \%$ of the bioindicator research papers published between 1970-2005 have dealt with metal pollution. ${ }^{10}$ Among bioindicators benthic foraminifera, single-celled eukaryotes, have been shown to be suitable and reliable proxies of pollution impacts in marine and transitional marine environments. ${ }^{11,12}$ The response of benthic foraminifera to adverse ecological conditions including pollution may be investigated in terms of density and diversity, assemblage composition, reproductive capability, test morphologic abnormality, test geochemistry, test size (dwarfism), prolocular morphology, cellular ultrastructure, and pyritization. ${ }^{13-15}$ Although major advances have been achieved over 50-60 years, we are still far from fully understanding the benthic foraminiferal response to pollution. Moreover, little is known about the cytological changes induced in foraminifera by exposure to sublethal heavy metal concentrations. ${ }^{16-20}$ In particular, living specimens of Ammonia tepida were cultured and exposed to different concentrations of oil fuel spilled during the oil tanker Erika accident in 1999. ${ }^{17}$ They documented a compact and homogeneous inner organic layer (IOL) in the
Correspondence: Prof. Elisabetta Falcieri, DiSTeVA, University of Urbino Carlo Bo, via Ca' le Suore, 61029 Urbino (PU), Italy.

Tel. +39.0722.304284 - Fax: +39.0722.304244.

E-mail: elisabetta.falcieri@uniurb.it

Key words: Foraminifera, pollution, ultrastructure, mesocosm.

Contributions: EF and RC contributed equally to this work; FF, foraminiferal analysis and manuscript writing; DC, TEM and ESEM-EDS analyses, manuscript writing; FMG, laboratory treatment; JMB, data interpretation; EF, data interpretation and coordination; RC, project coordinator.

Conflict of interest: the authors declare no conflict of interest.

Acknowledgements: this research was partially supported by the PRIN 2010-2011 Ministero dell'Istruzione, dell'Università e della Ricerca (MIUR) (protocollo 2010RMTLYR) to R.C. and by US NSF grant OCE-1219948 to J.M.B. The authors are indebted to Laura Valentini for skillful technical assistance.

Received for publication: 20 November 2014. Accepted for publication: 15 December 2014.

This work is licensed under a Creative Commons Attribution NonCommercial 3.0 License (CC BYNC 3.0).

(C) Copyright F. Frontalini et al., 2015

Licensee PAGEPress, Italy

European Journal of Histochemistry 2015; 59:2460 doi:10.4081/ejh.2015.2460

control culture and a thickening of it due to infilling of fibrous material and a proliferation of residual bodies in the oil-contaminated cultures. The IOL represents the insoluble organic matrix found between the test and the cytoplasm $^{21}$ and is mainly composed of protein and polysaccharides, bound together in a complex macromolecular structure. ${ }^{22}$ It was inferred that the thickening of the IOL might have acted as a defense mechanism against penetration of xenobiotic components (pollutants) in the cell whereas the enhanced occurrence of residual bodies might have resulted from a metabolic perturbation. ${ }^{17}$ The morphological and cytological responses of two Ammonia species exposed to different $\mathrm{Cu}$-concentrations were analyzed by Le Cadre and Debenay. ${ }^{19}$ They documented an increase in test abnormalities and a delay in chamber production and reproduction, as well as marked cytological modifications in deformed specimens. These changes include thickening of IOL, fibrillar and large lipidic vesicle proliferation, and increased number of residual bodies. They were also able to detect sulfur in deformed 
specimens that was related to a metallothionein-like protein mediated detoxification mechanism. Most investigations have been based on monospecific culture experiments where benthic foraminiferal species are directly exposed to artificial seawater contamination regardless of their natural environments (sediments). On the other hand, mesoand microcosm experiments in which heavymetal pollution was simulated under controlled environmental conditions where benthic foraminifera were kept as far as possible in natural conditions (i.e., original sediments) have been rarely conducted. ${ }^{23-26}$

The main aim of this preliminary investigation is to document the cytological response of the benthic foraminiferal species Ammonia parkinsoniana when cultured in mesocosms and when exposed to selected concentrations of $\mathrm{Pb}$ over time. This paper further aims to determine if any cytological modification was induced when the species was removed from its natural environment and cultured in laboratory mesocosms.

\section{Materials and Methods}

\section{Sediment sampling and laboratory lead treatment}

Sediment samples were collected at $14-\mathrm{m}$ water depth off the Monte Conero area (Italy, Adriatic Sea). The collection site is a coastal area located close to the National Park of Monte Conero, a protected natural area characterized by low influence of human activity, largely diversified benthic foraminiferal assemblages and oligo-mesotrophic conditions. ${ }^{27}$ At the collection site, temperature, $\mathrm{pH}$, salinity, Eh and dissolved oxygen of seawater were measured in vertical profile using a multiparametric CTD (Conductivity, Temperature and Depth) probe. Sediment was sampled by Van Veen grab sampler that collects sediment over a surface area of about $400 \mathrm{~cm}^{2}$ and only the first $2 \mathrm{~cm}$ was retained. 0 n board, the sediment was homogenized and sieved over a $500-\mu \mathrm{m}$ screen. The $>500 \mu \mathrm{m}$ fraction was discarded to remove potentially disturbing effects of bioturbators (i.e., macrofauna and large meiofauna). The $<500 \mu \mathrm{m}$ fraction, which bears foraminifera, was placed in an insulated box covered by ambient seawater, and kept near ambient temperature until arrival at our shore-based laboratory.

Artificial Sea Water (ASW) was prepared following the methods of Ciacci et al., ${ }^{28}$ stored in the dark, aerated and mixed under in situ temperature. A total of seven different Pb-ASW mixture concentrations plus control $(<4 \mathrm{ppb})$ were prepared. Inorganic salt of $\mathrm{Pb}$ as lead chloride $\left(\mathrm{PbCl}_{2}\right) 98 \%$ pure was used for the experiments
(CAS Number 7758-95-4; Sigma-Aldrich, St. Louis, M0, USA). The final pollutant concentrations for experimental media were obtained by adding appropriate volumes of stock solutions to ASW. The selected concentrations were 10 ppb, 100 ppb, 200 ppb, 500 ppb, 1 ppm, 5 ppm, and $10 \mathrm{ppm}$. Approximately 20L of Pb-ASW mixture was introduced into each tank (aquarium) $(60 \mathrm{~cm} \times 40 \mathrm{~cm} \times 20 \mathrm{~cm})$. A total of twelve mesocosms $(15 \mathrm{~cm} \times 8 \mathrm{~cm} \times 3 \mathrm{~cm})$ containing $1 \mathrm{~cm}$ thick sediment were placed inside each tank. Multichannel pumps were used to circulate and to oxygenate water through silicone rubber tubing anchored between the tanks' bottom and plastic grids. Tanks were placed in a controlled environment with air temperatures of $14-16^{\circ} \mathrm{C}$ that were uniformly maintained throughout the experiment. The dissolved oxygen (D0), salinity (S), conductivity, temperature (T), ORP and $\mathrm{pH}$ of the seawater were routinely monitored by a set of HQ40d portable multi-parameter probes.

\section{Mesocosm experiment}

Sampling of the experimental mesocosms involved a number of steps that were followed at each time point of the experiment. One mesocosm was processed as described below at preestablished time intervals: one week (W1), three weeks (W3) and eight weeks (W8) from both the control (c) and three selected concentrations of Pb-pollutants (1 ppb, $1 \mathrm{ppm}$, and 10 ppm). Each sample was labeled with the contaminant identification $(\mathrm{Pb})$, followed by nominative concentrations and time of sampling (W1, W3, W8) whereas the original samples were labeled as W0. The $120-\mathrm{cm}^{3}$ sediments from each mesocosm were wet-sieved with ASW through a 125 - $\mu \mathrm{m}$ net to remove finer materials. At least $30 \mathrm{~A}$. parkinsoniana specimens were hand-picked with a fine brush from each sample. Ammonia parkinsoniana was selected for its great abundance and hyaline nature of its test that eases the recognition of cytoplasmbearing specimens. The presence of cytoplasm in any chamber but the last one was chosen as the criterion for evaluating the viability of the specimens. The selected Ammonia specimens had a yellowish cytoplasm visible by transparency through the test. Different methodologies for the recognition of living specimens of benthic foraminifera have been proposed and can be divided in terminal and non-terminal methods. ${ }^{29}$ The choice of methods depends on the study aim and non-terminal methods would be more appropriate for isolating specimens for laboratory experiments. ${ }^{30}$ These methods include natural coloration, apertural bolus, negative geotaxis, positive phototaxis, cytoplasmic streaming, reticulopodial networks, and fluorogenic probes..$^{29,31}$ The natural coloration is due to the presence of cytoplasm, endosymbionts, sequestered chloroplasts and food and was selected for this investigation to discriminate living from dead foraminifera. Although quick and inexpensive, the application of this methodology might result in the misinterpretation of living foraminifera. ${ }^{29}$ Ultrastructure observations in terms of appearance, abundance, and organization of organelles provide useful information on the specimen viability. ${ }^{29}$ As mitochondria are among the first organelles to degrade, their presence with intact conditions confidently suggests specimens' viability but the rupture of mitochondria or degraded organelles does not necessary imply dead specimens. ${ }^{29}$ For this reason, it was decided to refer to cytoplasm-containing specimens rather than living ones.

\section{Microscopic analyses}

\section{Transmission Electron Microscopy (TEM)}

Picked specimens were fixed with $2.5 \%$ glutaraldehyde (TAAB Laboratories Equipment Ltd., West Berkshire, UK) in ASW for $3 \mathrm{~h}$ at $4^{\circ} \mathrm{C}$. After 5 washings with ASW, foraminiferal specimens were post-fixated with $1 \%$ osmium tetroxide $\left(\mathrm{OsO}_{4}\right.$; EMS, Hatfield, PA, USA) in ASW for $2 \mathrm{~h}$ at room temperature. Following 5 washings, specimens were dehydrated in a graded series of ethanol baths, from $50 \%$ to $100 \%$ and immersed in propylene oxide (EMS) for 2 times, 10 min each. Subsequently, they were embedded in epoxy resin by using increasing concentration of resin (Durcupan Araldite, SigmaAldrich). Foraminifera were ultimately sectioned using an ultramicrotome (LKB, 2088 Ultrotome $\left.{ }^{\circledR V}\right)$. Thick sections of $1 \mu \mathrm{m}$ were stained with $1 \%$ toluidine blue in distilled water at $60^{\circ} \mathrm{C}$ to provide an overall specimen observation at the light-microscope level. Thin sections $(100 \mathrm{~nm})$, collected on 300-mesh nickel grids, were stained with uranyl acetate and lead citrate and finally observed with a Philips CM10 electron microscope at $80 \mathrm{KV}^{32}$

\section{Environmental Scanning Electron Microscopy (ESEM) and Energy Dispersive Spectrometer (EDS)}

Embedded specimens of W8-10 ppm were observed with an environmental scanning electron microscope (FEI ESEM, Quanta 200) to qualitatively characterize the occurrence of trace element nanoparticles or foreign elements within the foraminifera. The ESEM, coupled with an energy dispersive spectrometer (EDS), was used to assess the chemical composition of particles within the foraminiferal test. The EDS is a technique employed to collect and determine the energy and the number of $\mathrm{X}$-rays that are given off by atoms in a material. ${ }^{33}$ The observation was carried out in low vacuum (0.21.2 Torr) conditions, secondary and backscattered electron mode with energy varying from 12 to $25 \mathrm{kV}$, at $10 \mathrm{~mm}$ working distance. live counting time of $100 \mathrm{~s}$ with spots from 3 to 5 . 


\section{Results}

\section{Transmission Electron Microscopy}

After 60 days of culture, we did not note any cytological differences between specimens from the natural environment and those of W8c. In fact, at the ultrastructural level, in the cultured specimens the cytoplasmic distribution of organelles as well as their morphology appeared to be comparable to those that lived in the sea (natural environment). Analyzing the specimens at TEM (Figure 1 A,B), the general cell organization displayed the presence of lipid droplets, residual bodies, mitochondria, vacuoles, and Golgi apparatus. The densities of organelles seemed to be the same in both conditions. At higher magnification, it was possible to evaluate the specific features of each organelle and these data might reveal information regarding the foraminiferal health. In particular, we focused on some of the typical organelles that play a key role in the foraminiferal life, such as mitochondria, Golgi apparatus, and residual bodies. The presence of the latter has been revealed in both groups and their ultrastructure appeared comparable (Figure $1 \mathrm{C}, \mathrm{D}$ ). Mitochondria of both conditions, frequently distributed in small groups near the pores, showed outer and inner membranes as well as the typical tubular cristae in the matrix (Figure $1 \mathrm{E}, \mathrm{F}$ ), and similarly, the Golgi apparatus (Figure $1 \mathrm{G}, \mathrm{H}$ ) appeared to be undamaged, with a regular arrangement of cisternae. No differences in the morphology of the inner organic lining (IOL) and pores were noted between groups (Figure $1 \mathrm{I}, \mathrm{L}$ ).

On the other hand, numerous morphological differences were observed between control and lead-treated samples. These differences are particularly evident when W8-c and W8-10 ppm are compared. Foraminifera from lead treatments revealed more cytoplasmic degradation in the younger chambers compared to the control group and, at low magnification, the cytoplasm of the Pb-treated foraminifera appeared to display an increased number of lipid droplets (Figure $2 \mathrm{~A}, \mathrm{~B}$ ). These bodies were surrounded by a distinct membrane that seemed to be thicker in the Pb-treated group in comparison to the control. In addition, the lipid droplets of the Pb-treated group revealed an electron-dense core that was not, however, visible in the control specimens (Figure 2 C,D). At higher magnification, other ultrastructural differences could be highlighted between $\mathrm{Pb}$ treated and untreated specimens. In particular, while mitochondria of the control group displayed typical distributions and morphology, characterized by a double external membrane and tubular cristae, the Pb-treated specimens showed regular and typical organelles in the older chambers, but in the younger, these
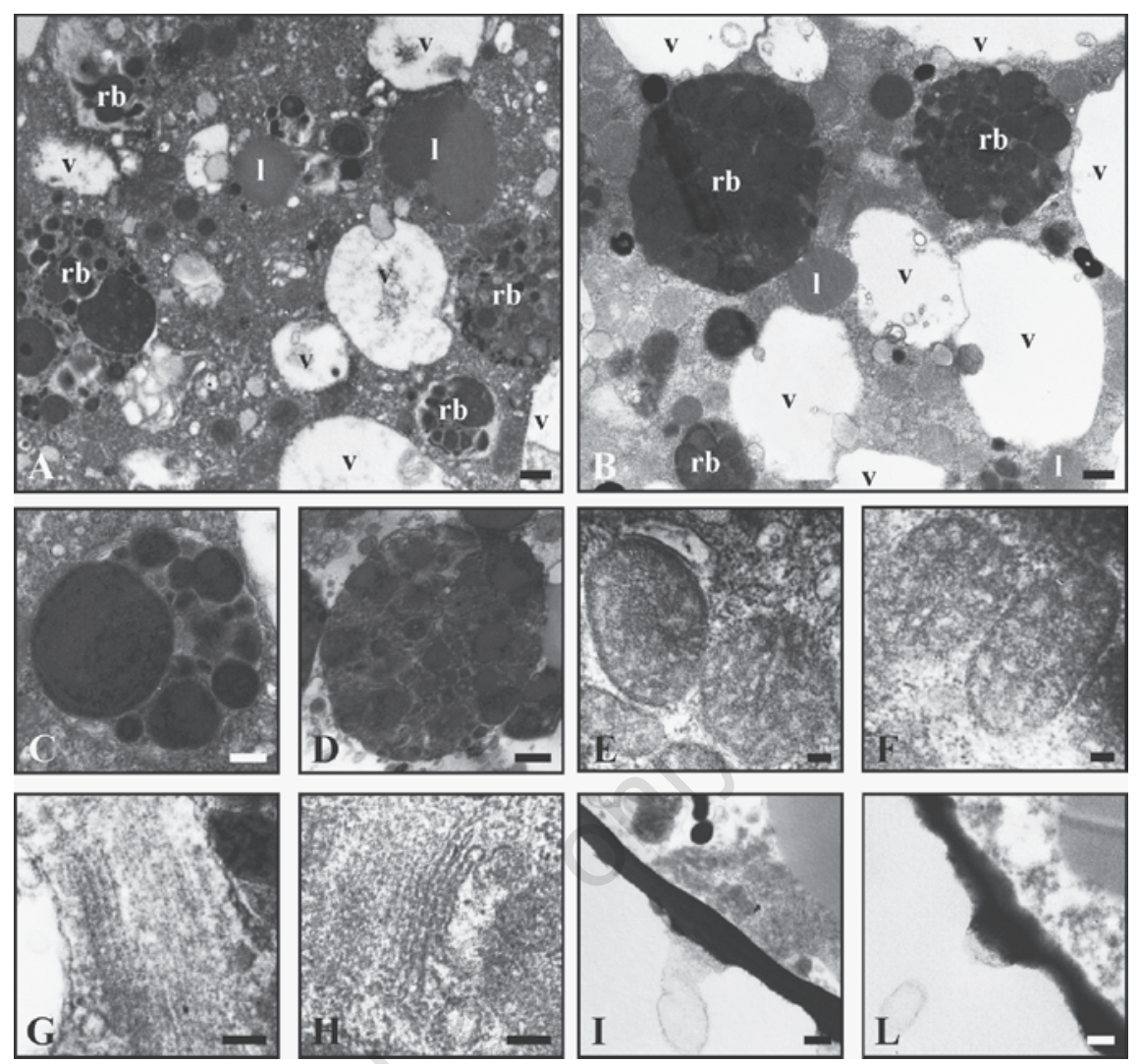

Figure 1. Low magnification (A, B) of cytoplasm from foraminifera directly selected from the original sediment $(A, C, E, G, I)$ and maintained in mesocosm $(B, D, F, H, L)$. Residual bodies (rb), vacuoles (v) and lipids (l). At high magnification (C-F), residual bodies $(C, D)$, mitochondria $(E, F)$, Golgi apparatus $(G, H)$ and organic lining with pore (I, L). Scale bars: A, B) $1.25 \mu \mathrm{m}$; C, D, I, L) $250 \mathrm{~nm}$; E, F) $100 \mathrm{~nm}$; G, H) $125 \mathrm{~nm}$.
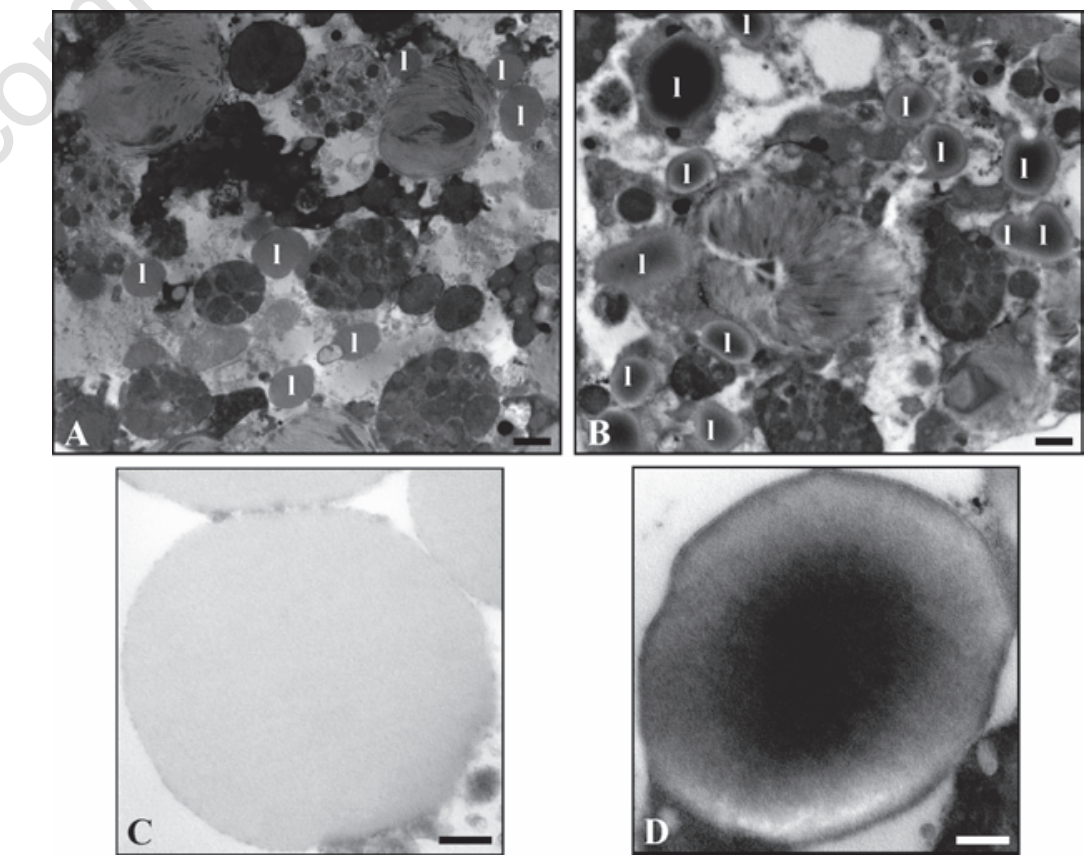

Figure 2. The amount of lipid vacuoles (I) appears lower in the control (A) compared to the polluted samples (B). High magnification of lipid droplets in untreated specimens (C) and treated ones (D), which show an electron-dense core and a well-defined membrane. Scale bars: A, B) $1 \mu \mathrm{m}$; C, D) $250 \mathrm{~nm}$. 
appear quite degraded, losing the continuity of double membrane as well as the cristae integrity, the amount of which was reduced (Figure $3 \mathrm{~A}, \mathrm{~B}$ ). The thickness of the IOL was variable among the chambers but specimens of the W8-10ppm group displayed a general thickening of the IOL in comparison to W8-c although this structure did not appear morphologically different in the two conditions (Figure $3 \mathrm{C}, \mathrm{D}$ ). An increased number of residual bodies and membrane-like organelles, tentatively interpreted as putative lipofuscin, were revealed in the W8-10 ppm specimens. Residual bodies of different sizes were observed, delimited by a prominent membrane that enclosed different indigestible materials and degraded organelles (Figure 4A), while putative lipofuscins displayed a variable number of lipid-containing residues that might appear at different state of degradation (Figure 4B). In the $\mathrm{Pb}$-treated conditions, a higher number of organelles interpreted as autophagosomes (Figure 4C) and small electron-dense accumulations (Figure 4D) were detected.

Analyzing the younger chambers of W8-10 ppm specimens exhibiting degraded organelles, framboidal aggregations were noted (Figure 5A). These aggregates were characterized by the presence of numerous electron-dense crystallites, each of which appeared to be contained within its own membrane (Figure 5B).

\section{Environmental Scanning Electron Microscopy and Energy Dispersive Spectrometer}

On the basis of ESEM observation, it was possible to reveal the presence of several masses within the same foraminiferal chamber; masses were characterized by different diameters (from 2 to $30 \mu \mathrm{m}$ ) and variable crystal sizes (from 0.2 to $2 \mu \mathrm{m}$ ). Moreover, the shape of each single granule appeared like a crystal with a regular form (Figure $5 \mathrm{C}$ ). The EDS-microanalysis shows the qualitative elemental composition of these structures that are constituted of Fe and $\mathrm{S}$. These structures are equidimensional pyrite, iron sulfide $\left(\mathrm{FeS}_{2}\right)$ microcrystals (Figure 5D), organized in framboidal aggregates.

\section{Discussion}

\section{Does the laboratory-controlled environment induce cytological modification in Ammonia parkinsoniana?}

The cytoplasmic distribution of organelles, as well as their morphology, of A. parkinsoni- ana specimens preserved directly from the original sediment (W0) immediately after sampling and those maintained in mesocosm after 60 days, did not display any appreciable ing residual bodies, mitochondria, vacuoles and Golgi apparatus, and other structures like the IOL, not only seemed to be unaffected from a morphological perspective, but even their abundance appeared to be consistent when natural and cultured specimens were compared. According to our results, we can confidently suggest that the cultivation of this species in a laboratory-controlled setting (mesocosms) where conditions were maintained as similar to in situ conditions as possible, did not induce any detectable cytological modifications.

\section{Does $\mathrm{Pb}$-pollution induce cytologi-} cal and/or ultrastructure alteration on Ammonia parkinsoniana?

The response of benthic foraminifera to pollution is commonly analyzed at the assemblage level and only a limited number of studies have focused on the response at the species level by
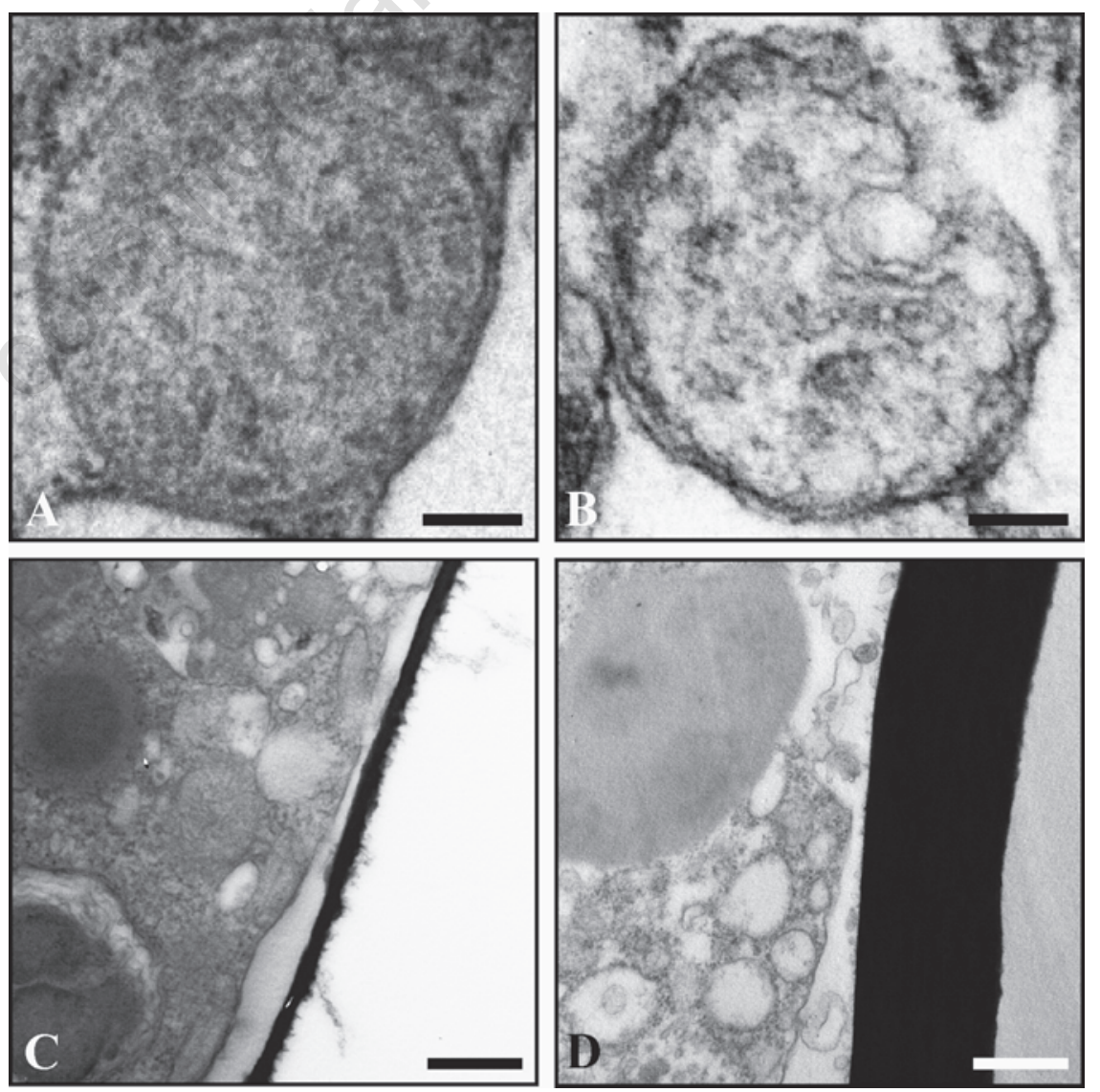

Figure 3. High magnification of intact (A, control) and degraded (B, treated) mitochondria. Organic lining in control (C) appears thinner if compared to the treated group (D). Scale bars: A, B) $100 \mathrm{~nm}$; C, D) $500 \mathrm{~nm}$.

evaluating the modification of organelle morphology and their distribution. Moreover, most of these studies have been conducted on selected species removed from their natural environments (sediment) and cultured/incubated in microfiltered seawater in Petri dishes. Our study was conversely based on the direct exposure of sediments containing living populations of benthic foraminiferal species as those found in natural environments. Heavy metals including $\mathrm{Pb}$ could penetrate the foraminiferal test, potentially resulting in cytological modifications. ${ }^{16,19}$ Accordingly, in our study here we show several cytological and ultrastructure differences were evident when control and treated samples were compared.

The Pb-treated specimens exhibited a higher number of lipid droplets surrounded by a membrane that appeared to be thicker than in the control specimens. The occurrence of the lipid droplets (vesicles) have been interpreted as a perturbation in the regulation metabolism of foraminiferal specimens contaminated by copper. ${ }^{19}$ In addition, the lipid droplets of the treated group revealed a more electron-dense core, which was not visible in the control specdifferences. The analyzed organelles, includ-

[page 4]

[European Journal of Histochemistry 2015; 59:2460] 
imens. It might be hypothesized that the more electron-dense core of lipid droplets might serve for storing pollutants. Lipids and proteins of very electron-dense membranes have been inferred to sequester excess intracellular cations in the cyanobacterium Plectonema boryanum exposed to different trace elements (i.e., $\mathrm{Co}, \mathrm{Zn}, \mathrm{Hg}, \mathrm{Cd}$, Ni or $\mathrm{Cu}$ ). ${ }^{34}$ These structures were suggested to indicate a detoxification mechanism where the toxic free cations could have been neutralized or immobilized and therefore rendered non-toxic. ${ }^{4}$

Interestingly, these accumulations were reported as surrounded by a membrane similar to our observations. It was also suggested that the lysosomal system and residual bodies might act as storing heavy metals not only in foraminifera but in other groups of organisms including mussels, oysters, marine dinoflagellates. ${ }^{19}$ On the basis of the proliferation of residual bodies in foraminifera exposed to high concentration of $\mathrm{CuCl}_{2}$, these authors postulated either a detoxification mechanism or metabolic perturbations. Lysosomes are responsible for the degradation of redundant or damaged organelles and proteins as part of autophagy as well as in sequestering and accumulating pollutants. ${ }^{35,36}$ It has also been suggested that the organic lining might have a protective role against harmful agents, ${ }^{37}$ according to our observations, treated specimens exhibited a general thickening when compared to control specimens even though there was variable IOL thickness among different chambers of $\mathrm{Pb}$-treated specimens. The same IOL modification was noted in cultured specimens of Ammonia tepida exposed to oil fuel and in two species of Ammonia (A. tepida and $A$. beccarii) exposed to copper. ${ }^{17,19}$ They document a fibrous texture of the thickened organic lining whereas we observed no change in IOL texture. A thickened and laminated organic lining was also documented in Cassidulina neocarinata from bathyal hydrocarbon seeps of Green Canyon (Gulf of Mexico) as a form of protection to hydrocarbon seep activity. ${ }^{38}$ According to all these prior observations, a protective role of the thickened organic lining against the penetration of $\mathrm{Pb}$ might be inferred.
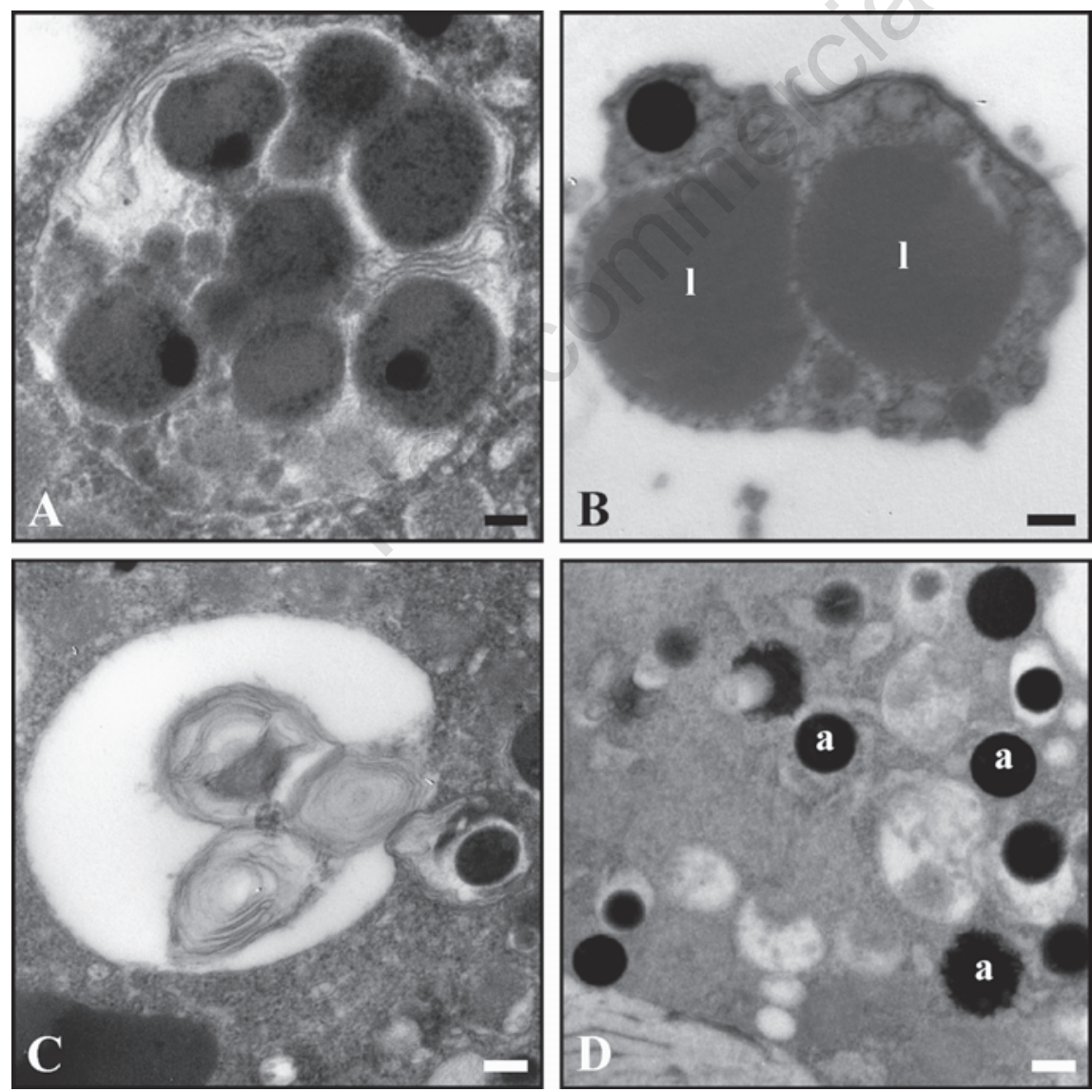

Figure 4. Residual body (A), lipofuscin (B), autophagic vacuole (C) and electron-dense accumulations (D, a) are observed in treated specimens. Scale bars: A) $125 \mathrm{~nm}$; B-D) $250 \mathrm{~nm}$.

Loss of continuity of double membrane and cristae integrity in mitochondria is among the relevant morphological modifications observed in Pb-treated specimens. Disintegration of cristae and/or mitochondrial degradation has been reported in other organisms like ciliates exposed to pollutants. ${ }^{4}$ Heavy metals might induce the formation of reactive oxygen species (ROS) that can induce oxidative damage to DNA, proteins and lipids up to cellular death. ${ }^{39,40}$ Some authors have suggested that mitochondria might be among the cellular organelles most affected by ROS. ${ }^{41,42}$ Abeliovich and Klionsky suggested that autophagy is a major pathway for mitochondrial breakdown. ${ }^{43}$ Therefore, autophagy may be the mechanism for degrading mitochondria altered by ROS production. It is worth noting, that $\mathrm{Pb}$ among other pollutants $(\mathrm{Cd}, \mathrm{Cr}$, anthracene and pyrene) were reported to promote oxidative stress and induce lysosomal membrane disruption in the free-living marine ciliate Euplotes crassus. ${ }^{36}$

A higher number of some membrane-like organelles, tentatively interpreted as lipofuscin, have been recognized within treated specimens. The interpretation of these membranelike organelles as putative lipofuscin was morphological and not chemical nor via pigmentation occurrence. These organelles displayed a variable number of lipid residues likely from lysosomal digestion. Lipofuscins have been reported as the product of the oxidation of unsaturated fatty acids, and are commonly associated with membrane, mitochondria and lysosome damage. ${ }^{44}$ They might also contain metals. ${ }^{44}$ Lipofuscins, basically composed of non-oxidable lipids, represent one of the main cellular products accumulating in lysosomes as a result of the oxidative stress caused by pollutants. ${ }^{35,45,46}$ Moreover, they are inferred to contribute to metal detoxification, being either enclosed within residual bodies or extruded into the extracellular space. ${ }^{47}$ These organelles have been also recorded in a fresh water flagellated protist (Euglena gracilis), a mussel (Mytilus galloprovincialis), and a sea urchin. ${ }^{48,49}$ Another significant cytological alteration is represented by the increased numbers of autophagosomes. The formation of autophagosomes has been related either to a specific mechanism induced by starvation or nutritional stress or to programmed cell death. ${ }^{43,50}$ Autophagosomes are therefore responsible for the intracellular degradation of cytoplasmic contents including altered intracellular proteins, excess or damaged organelles. It might be speculated that benthic foraminifera like other eukaryotes under stress conditions might use autophagic mechanisms for degrading ROS-affected mitochondria induced by heavy metal pollution. Dense occurrence of peroxisomes, particularly in the 
younger chambers and at the periphery of vacuoles, was inferred as one biochemical filter, facilitating the breakdown of environmental ROS (i.e., $\mathrm{H}_{2} \mathrm{O}_{2}$ ), and therefore protecting the endoplasm from ROS. ${ }^{51}$ All the ultrastructural modifications induced by $\mathrm{Pb}$ share similarities to several ciliate species and might be linked to active cell death (apoptosis) that is associated with intense autophagic activity. ${ }^{4}$

The cytoplasm observation of treated specimens revealed the presence of more electrondense globular small accumulations that might be tentatively interpreted as putative $\mathrm{Pb}$ granules. Electron-dense irregular deposits related to metallic accumulation were noted in three ciliate species (Colpoda steinii, Cyrtolophosis elongata and Drepanomonas revolute).,52 In addition, these deposits were also recognized in another ciliate species, Tetrahymena, when exposed to $\mathrm{Pb}^{53}$ They have also been observed in certain microalgae (Dunaliella bioculata) after treatment with $\mathrm{Cd} .{ }^{54}$ Interestingly, some aggregates of inorganic material were observed during TEM analysis that were ultimately determined to be composed of iron and sulphur in the ESEM-EDS microanalysis and
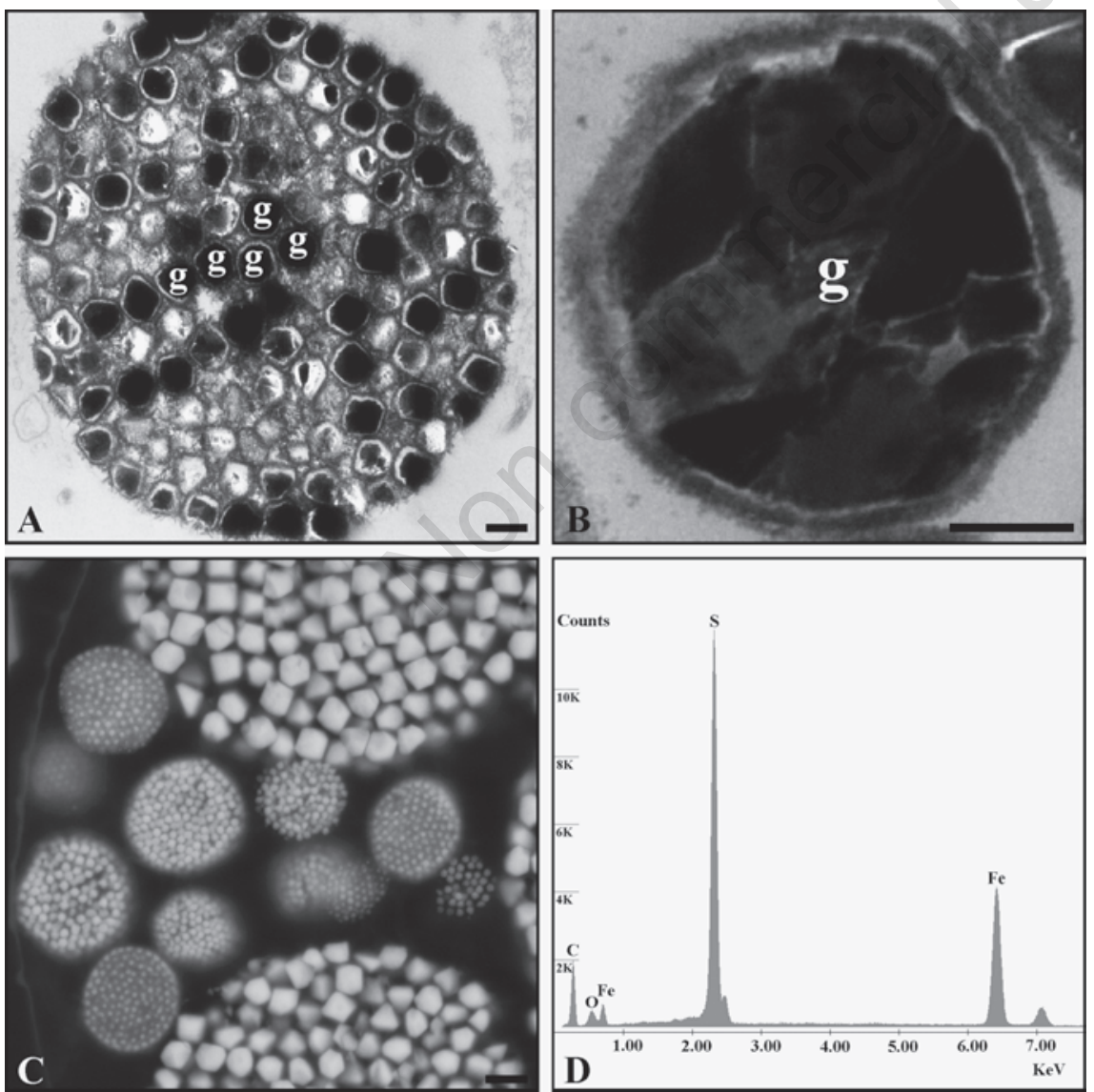

Figure 5. TEM analysis of framboidal aggregates (A) of pyrite granule (g) (B) are observed within chambers of treated specimens. ESEM analysis displays numerous aggregate within the same chamber (C) and the EDS-microanalysis (D) reveals the nature of this accumulation. Scale bars: A) $500 \mathrm{~nm}$; B) $125 \mathrm{~nm}$; C) $2.5 \mu \mathrm{m}$. lessonii exposed to zinc. ${ }^{60}$ Metallothionein is a family of cysteine-rich, low molecular weight proteins which have the capacity to bind trace elements through the thiol (-SH) group of its cysteine residues and thus decrease the toxic effect of trace elements. ${ }^{61-63}$ It can also act as a scavenger of free radicals and reactive oxygen metabolites. ${ }^{64,65}$ The pyritization of foraminiferal tests might also have resulted from microbial activity during degradation of foraminiferal cytoplasm.

\section{Conclusions}

The responses of one benthic foraminiferal species (Ammonia parkinsoniana) exposed to different concentrations of $\mathrm{Pb}$ were evaluated at cytological levels. On the basis of TEM and ESEM-EDS analyses, it was possible to recognize numerous morphological differences between control and lead-treated specimens. The highest $\mathrm{Pb}$-concentration led to an increase in the number of lipid droplets also marked by a more electron-dense core, a proliferation of residual bodies, a thickening of the organic lining, a loss of continuity of double membrane and cristae integrity on mitochondria, a proliferation of autophagosomes and the occurrence of inorganic aggregates. All these cytological modifications might be related to the pollutant-induced stress and some of them such as the thickening of organic lining might suggest a potential mechanism of protection adopted by foraminifera to metal exposure.

\section{References}

1. Hill MK. Understanding environmental pollution. A primer. Cambridge University Press, 2004.

2. Stankovic S, Kalaba P, Stankovic AR. Biota as toxic metal indicators. Environ Chem Lett 2014;12:63-84.

3. Kong IC, Bitton G, Koopman B, Jung KH. Heavy metal toxicity testing in environmental samples. Rev Environ Contam Toxicol 1995;142:119-47.

4. Martín-González A, Borniquel S, Díaz S, Ortega R, Gutiérrez JC. Ultrastructural alterations in ciliated protozoa under heavy metal exposure. Cell Bio Int 2005; 29:119-26.

5. Holland HA, Schöne BR, Marali S, Jochum KP. History of bioavailable lead and iron in the Greater North Sea and Iceland during the last millennium - A bivalve sclerochronological reconstruction. Mar Poll Bull 2014;87:104-16. 
6. Harrison RM. Pollution: causes, effects and control. Royal Society of Chemistry, 2001.

7. Fernandez-Leborans G, Novillo A. Effects of periodic addition of lead on a marine protistan community. Aquat Sci 1994;56: 191-205.

8. Lidsky TI, Schneider JS. Lead neurotoxicity in children: basic mechanisms and clinical correlates. Brain 2003;126:5-19.

9. Flora G, Gupta D, Tiwari A. Toxicity of lead: a review with recent updates. Interdiscip Toxicol 2012;5:47-58.

10. Burger J. Bioindicators: a review of their use in the environmental literature 19702005. Env Bioind 2006;2:136-44.

11. Uthicke S, Thompson A, Schaffelke B. Effectiveness of benthic foraminiferal and coral assemblages as water quality indicators on inshore reefs of the Great Barrier Reef, Australia. Coral Reefs 2010;29:209-25.

12. Frontalini F, Coccioni R. Benthic foraminifera as bioindicators of pollution: a review of Italian research over the last three decades. Rev Micropal 2011;54:115-27.

13. Alve E. Benthic foraminiferal responses to estuarine pollution: a review. J Foram Res 1995;25:190-203.

14. Yanko V, Arnold AJ, Parker WC. Effects of marine pollution on benthic Foraminifera, p. 217-35. In: B.K. Sen Gupta (ed.), Modern Foraminifera. Dordrecht, Kluwer Academic Publ., 1999.

15. Frontalini F, Buosi C, Da Pelo S, Coccioni R, Cherchi A, Bucci C. Benthic foraminifera as bio-indicators of trace element pollution in the heavily contaminated Santa Gilla lagoon (Cagliari, Italy). Mar Poll Bull 2009;58:858-77.

16. Bresler V, Yanko V. Acute toxicity of heavy metals for benthic epiphytic foraminifera Pararotalia spinigera (Le Calvez) and influence of seaweed-derived DOC. Env Tox Chem 1995;14:1687-95.

17. Morvan J, Le Cadre V, Jorissen F, Debenay JP. Foraminifera as potential bio-indicators of the "Erika" oil spill in the Bay of Bourgneuf: field and experimental studies. Aquat Living Resour 2004;17:317-22.

18. Saraswat R, Kurtarkar SR, Mazumder A, Nigam R. Foraminifers as indicators of marine pollution: a culture experiment with Rosalina leei. Mar Poll Bull 2004;48: 91-6.

19. Le Cadre V, Debenay JP. Morphological and cytological responses of Ammonia (foraminifera) to copper contamination: Implication for the use of foraminifera as bioindicators of pollution. Env Poll 2006; 143:304-17.

20. Nigam R, Linshy VN, Kurtarkar SR, Saraswat R. Effects of sudden stress due to heavy metal mercury on benthic foraminifer Rosalina leei: laboratory cul- ture experiment. Mar Poll Bull 2009;59: $362-8$.

21. Spindler M. The development of the organic lining in Heterostegina depressa (Nummulitidae: Foraminifera). J Foram Res 1978;8:258-61.

22. Ní Fhlaithearta S, Ernst SR, Nierop KGJ, de Lange GJ, Reichart GJ. Molecular and isotopic composition of foraminiferal organic linings. Mar Micropal 2013;102:69-78.

23. Gustafsson M, Dahllöf I, Blanck H, Hall P, Molander S, Nordberg K. Benthic foraminiferal tolerance to tri-n-butyltin (TBT) pollution in an experimental mesocosm. Mar Poll Bull 2000;40:1072-5.

24. Ernst SR, Morvan J, Geslin E, Le Bihan A, Jorissen FJ. Benthic foraminiferal response to experimentally induced Erika oil pollution. Mar Micropal 2006;61:76-93.

25. Topping JN, Murray JW, Pond DW. Sewage effects on the food sources and diet of benthic foraminifera living in oxic sediment: a microcosm experiment. J Exp Mar Biol Ecol 2006;329:239-50.

26. Frontalini F, Coccioni R. The response of the benthic foraminiferal community to copper exposure: the mesocosm experience. J Env Prot 2012;3:342-352.

27. Frontalini F, Coccioni R. Benthic foraminifera for heavy metal pollution monitoring: a case study from the central Adriatic Sea coast of Italy. Est Coast Shelf Sci 2008;76:404-17.

28. Ciacci C, Canonico B, Bilani ov D, Fabbri $\mathrm{R}$, Cortese K, Gallo G, et al. Immunomodulation by different types of $\mathrm{N}$-oxides in the hemocytes of the marine bivalve Mytilus galloprovincialis. PLoS One 2012;7e36937.

29. Bernhard JM. Distinguishing live from dead foraminifera: methods review and proper applications. Micropaleontology 2000;46(Supp.1):38-46.

30. Murray JW. Ecology and applications of benthic Foraminifera. Cambridge University, New York, 2006.

31. Bernhard JM, Bowser SS. Novel epifluorescence microscopy method to determine life position of foraminifera in sediments. J Micropal 1996;15:68.

32. Salucci S, Battistelli M, Burattini S, Squillace C, Canonico B, Gobbi P, et al. C2C12 myoblast sensitivity to different apoptotic chemical triggers. Micron 2010; 41:966-73.

33. Goldstein JI, Newbury DE, Echlin P, Joy DC, Lyman CE, Lifshin E, Sawyer L, Michael JR. Scanning electron microscopy and $\mathrm{x}$-ray microanalysis. Kluwer Academic/Plenum Publ., New York, 2003.

34. Rachlin JW, Jensen TE, Baxter M, Jani V. Utilization of morphometric analysis in evaluating response of Plectonema boryanum (Cyanophyceae) to exposure to eight heavy metals. Arch Env Cont Tox 1982;11:323-33.

35. Moore MN, Icarus Allen J, McVeigh A. Environmental prognostics: an integrated model supporting lysosomal stress responses as predictive biomarkers of animal health status. Mar Env Res 2006;61: 278-304.

36. Gomiero A, Dagnino A, Nasci C, Viarengo A. The use of protozoa in ecotoxicology: application of multiple endpoint tests of the ciliate E. crassus for the evaluation of sediment quality in coastal marine ecosystems. Sci Tot Env 2013;442:534-44.

37. Leutenegger S. Ultrastructure de foraminifères perforés et imperforés ainsi que leurs symbiotes. Cahiers Micropal 1977;3: 1-52.

38. Sen Gupta BK, Platon E, Bernhard JM, Aharon P. Foraminiferal colonization of hydrocarbon-seep bacterial mats and underlying sediment, Gulf of Mexico slope. J Foram Res 1997;27:292-300.

39. Ercal N, Gurer-Orhan H, Aykin-Burns N. Toxic metals and oxidative stress part I: mechanisms involved in metal-induced oxidative damage. Curr Top Med Chem 2001;1:529-39.

40. Lesser MP. Oxidative stress in marine environments: biochemistry and physiological ecology. Annu Rev Physiol 2006;68: 253-78.

41. Bagchi D, Joshi SS, Bagchi M, Balmoori J, Benner EJ, Kuszynski CA, et al. Cadmiumand chromium-induced oxidative stress, DNA damage, and apoptotic cell death in cultured human chronic myelogenous leukemic K562 cells, promyelocytic leukemic HL-60 cells, and normal human peripheral blood mononuclear cells. J Biochem Mol Toxicol 2000;14:33-41.

42. Pinot F, Kreps SE, Bachelet M, Hainaut P, Bakonyi M, Polla BS. Cadmium in the environment: Sources, mechanisms of biotoxicity, and biomarkers. Rev Environ Health 2000;15:299-323.

43. Abeliovich H, Klionsky DJ. Autophagy in yeast: Mechanistic insights and physiological function. Microbiol Mol Biol Rev 2001;65:463-79.

44. Gaugler C. Lipofuscin. Stanislaus J Biochem Rev, 1997.

45. Gastaldi L, Ranzato E, Caprì F, Hankard P, Pérès G, Canesi L, et al. Application of a biomarker battery for the evaluation of the sublethal effects of pollutants in the earthworm Eisenia andrei. Comp Biochem Physiol C Toxicol Pharmacol 2007;146:398-405.

46. Pasteris A, Gambi N, Guerrini S, Bandini V, Buscaroli A, Dinelli E, et al. Linking responses at different levels of biological organization: the effect on biomarkers and 
life cycle traits in the earthworm Eisenia andrei exposed to copper-spiked soils. Comp Bioch Physiol Pt A 2008;151:48-53.

47. Moore MN. Cytochemical responses of the lysosomal system and NADPH ferrihemoprotein reductase in molluscan digestive cells to environmental and experimental exposure to xenobiotics. Mar Ecol Prog Ser 1988;46:81-9.

48. Vaschenko MA, Zhadan PM, Aminin DL, Almyashova TN. Lipofuscin-like pigment in gonads of sea urchin Strongylocentrotus intermedius as a potential biomarker of marine pollution: A field study. Arch Env Cont Tox 2012;62:599-613.

49. Peng C, Arthur DM, Sichani HT, Xia Q, Ng JC. Assessing benzene-induced toxicity on wild type Euglena gracilis $\mathrm{Z}$ and its mutant strain SMZ. Chemosphere 2013;93:2381-9.

50. Bursch W. The autophagosomal-lysosomal compartment in programmed cell death. Cell Death Differ 2001;8:569-81.

51. Bernhard JM, Bowser SS. Peroxisome proliferation in foraminifera inhabiting the chemocline: An adaptation to reactive oxygen species exposure? J Euk Microbiol 2008;55:135-44.

52. Martín-González A, Díaz S, Borniquel S, Gallego A, Gutiérrez JC. Cytotoxicity and bioaccumulation of heavy metals by ciliated protozoa isolated from urban waste- water treatment plants. Res Microbiol 2006;157:108-18.

53. Nilsson JR. Tetrahymena in cytotoxicology: with special reference to effects of heavy metals and selected drugs. Eur $\mathrm{J}$ Prot 1989;25:2-25.

54. Heuillet E, Moreau A, Halpern S. Cadmium binding to a thiol-molecule in vacuoles of Dunaliella bioculata contaminated with $\mathrm{CdCl}_{2}$ : electron probe microanalysis. Bio Cell 1986;58:79-86.

55. Schoonen MAA. Mechanisms of sedimentary pyrite formation. Special Paper of the Geological Society of America, 2004.

56. Merinero R, Lunar R, Martínez-Frías J, Somoza L, Díaz-del-Río V. Iron oxyhydroxide and sulphide mineralization in hydrocarbon seep-related carbonate submarine chimneys, Gulf of Cadiz (SW Iberian Peninsula). Mar Petr Geo 2008;25:706-13.

57. Kravchuk A. Benthic foraminifera as indicators of pollution in the northwestern shallow part of the Black Sea. Geoph Res Abstr 2006;8:00518.

58. Yanko V, Kronfeld J, Flexer A. Response of benthic foraminifera to various pollution sources: implications for pollution monitoring. J Foram Res 1994;24:1-17.

59. Buzas-Stephens P, Buzas MA. Population dynamics and dissolution of foraminifera in Nueces Bay, Texas. J Foram Res
2005;35:248-58.

60. Prazeres MDF, Martins SE, Bianchini A. Biomarkers response to zinc exposure in the symbiont-bearing foraminifer Amphistegina lessonii (Amphisteginidae, Foraminifera). J Exp Mar Biol Ecol 2011; 407:116-21.

61. Kumari MVR, Hiramatsu M, Ebadi M. Free radical scavenging actions of metallothionein isoforms I and II. Free Radic Res. 1998;29:93-101.

62. Coyle P, Philcox JC, Carey LC, Rofe AM. Metallothionein: The multipurpose protein. Cell Mol Life Sci 2002;59:627-47.

63. Ngu TT, Stillman MJ. Arsenic binding to human metallothionein. J Am Chem Soc 2006;128:12473-83.

64. Bresler V, Yanko V. Chemical ecology of foraminifera. Parameters of health, environmental pathology, and assessment of environmental quality, p. 217-254. In: E.M. Ronald (ed.) Environmental micropaleontology. Kluwer Academic/Plenum Publ., New York, 2000.

65. Colangelo D, Mahboobi H, Viarengo A, Osella D. Protective effect of metallothioneins against oxidative stress evaluated on wild type and MT-null cell lines by means of flow cytometry. BioMetals 2004; 17:365-70. 